\title{
OS SETE SABERES NECESSÁRIOS À EDUCAÇÃO DO FUTURO: REFLEXÕES E UM NOVO OLHAR SOBRE O TEMA
}

\author{
LOS SIETE CONOCIMIENTOS NECESARIOS A LA EDUCACIÓN DEL \\ FUTURO: REFLEXIONES Y UNA NUEVA IMAGEN SOBRE EL TEMA
}

\section{THE SEVEN KNOWLEDGE NEEDED FOR EDUCATION OF THE FUTURE: REFLECTIONS AND A NEW LOOK AT THE THEME}

\author{
Igor Leandro Alves de CARVALHO ${ }^{1}$ \\ Tânia Regina Souza ROCHA ${ }^{2}$ \\ Marcelo Borges ROCHA ${ }^{3}$
}

\begin{abstract}
RESUMO: Este artigo tem o propósito de reescrever as contribuições consensuais das personalidades universitárias nacionais e internacionais acerca das ideias de Edgar Morin que elegeu os sete saberes necessários à educação do futuro. Apresenta discussões que visam corroborar para o desenvolvimento da humanidade, da cidadania planetária e da ética indispensável ao enfrentamento das crises sociais e preservação da vida no planeta. Sensibilidade, diversidade cultural, pluralidade dos indivíduos, natureza transdisciplinar, relações e justiça sociais, preservação ambiental, os princípios e contradições do conhecimentosão temáticas necessárias e intrínsecas às práticas pedagógicas propulsoras de uma educação transformadora dos seres humanos e do mundo.
\end{abstract}

PALAVRAS-CHAVE: Educação. Ensinar. Saberes. Cidadania. Humanidade.

RESUMEN: En este artículo se pretende reescribir contribuciones consensuales de personalidades académicas nacionales e internacionales acerca de las ideas de Edgar Morin que eligieron el conocimiento de siete necesaria para la educación futura. Presenta debates destinados a corroborar el desarrollo de la humanidad, la ciudadanía global y la ética esenciales para hacer frente a la crisis social y la preservación de la vida en el planeta. La sensibilidad, la diversidad cultural, la pluralidad de las personas, la naturaleza transdisciplinaria, las relaciones y la justicia social, protección del medio ambiente, los principios y las contradicciones de la conhecimentosão temática necesaria e intrínseca a la conducción prácticas pedagógicas de educación transformadora de los seres humanos y el mundo.

PALABRAS CLAVE: Educación. Enseñanza. Conocimiento. La ciudadanía. La humanidad.

ABSTRACT: This article is intended to rewrite the consensus contributions of national and International University personalities about the ideas of Edgar Morin who elected the seven knowledge necessary for the education of the future. Features discussions aimed at support for the development of mankind, planetary citizenship and ethics essential to confronting the social crises and preservation of life on the planet. Sensitivity, cultural diversity, plurality of individuals, transdisciplinary nature, relations, and social justice, environmental preservation,

\footnotetext{
${ }^{1}$ Docente da Secretaria de Educação do Estado do Rio de Janeiro. Email: igor.leandro@yahoo.com.br

2 Especialista em Psicopedagogia. Docente da Secretaria de Educação do Estado do Rio de Janeiro. Email: taniarocha-inspetora@hotmail.com

3 Doutor em Ciências Biológicas. Docente do Programa de Pós-graduação em Ciência, Tecnologia e Educação do CEFET/RJ. Email: rochamarcelo36@yahoo.com.br
} 
the principles and contradictions of knowledge are necessary and intrinsic thematic pedagogic practices of propelling a transformative education of humans and the world.

KEYWORDS: Education. Teaching. Knowledge. Citizenship. Humanity.

\section{Introdução}

Neste artigo reescrevemos proposições de Edgar Morin consensuais às personalidades universitárias nacionais e internacionais, ao eleger os sete saberes necessários à educação do futuro. Morin (2011) introduz suas idéias mencionando que sua proposta é expor problemas centrais e ou fundamentais, que devem ser tratados por toda sociedade e cultura e que são necessários serem ensinados no próximo século. Abordam questões filosóficas, crenças religiosas das culturas e civilizações ao situar a condição humana, acrescentando a importância do saber científico.

Apresenta os Sete Saberes Necessários à Educação do Futuro em sete capítulos, abordando: 1. As cegueiras do conhecimento: destacando a importância do desenvolvimento de uma educação que introduza o estudo das características cerebrais, mentais, culturais dos conhecimentos humanos, incluindo seus processos e modalidades psíquicas e culturais; 2. Os princípios do conhecimento pertinente: defendendo que o conhecimento desenvolvido deve ser capaz de levar a apreensão dos objetos em seu contexto, complexidade e conjunto, desenvolvendo ainda a aptidão natural do espírito humano através de métodos que estabeleçam as relações mútuas e as influências entre as partes e o todo de um mundo complexo; 3. Ensinar a condição humana: enfatizando que a condição humana deve ser objeto de todo ensino. Evidencia o elo indissolúvel entre a unidade e a diversidade de tudo que é humano, baseando-se nas disciplinas atuais através da reunião e organização dos conhecimentos dispersos das ciências humanas e naturais, literaturas e da filosofia; 4. Ensinar a identidade terrena: Ressalta que é indispensável indicar o complexo da crise planetária, a importância da comunicação entre todos os continentes que carecem da solidariedadee discussão das opressões e dominações que ainda existem, apresentando aos seres humanos o destino comum; 5. Enfrentar as incertezas: Essencial ensinar princípios de estratégias que permitam o enfrentamento de imprevistos, inesperado e incertezas levando a modificação do seu desenvolvimento. $\mathrm{O}$ ensino das incertezas inclui as ciências físicas (microfísicas, termodinâmica e cosmologia), nas ciências da evolução biológica e 
ciências históricas; 6. Ensinar a compreensão: Esta é o meio e o fim da comunicação humana, que pede a reforma das mentalidades. O estudo da incompreensão com base em suas raízes, suas modalidades e seus efeitos, abordando as causas do racismo, xenofobia e do desprezo; 7. A ética do gênero humano: A educação deve levar a “antropoética"(indivíduo - sociedade - espécie). Todo desenvolvimento humano deve compreender o desenvolvimento conjunto das autonomias individuais, das participações comunitárias e da consciência de pertencer à natureza humana. Levar a consciência da "Terra-pátria" e a vontade de realizar a cidadania terrena.

Serão pauta do presente artigo as discussões que visam corroborar para o desenvolvimento da humanidade, da cidadania planetária e da ética indispensável ao enfrentamento das crises sociais e preservação da vida no planeta. Ademais destacaremos a diversidade cultural, pluralidade dos indivíduos, natureza transdisciplinar, relações e justiça sociais, preservação da natureza, os princípios e contradições do conhecimento às práticas pedagógicas significativas a uma educação transformadora dos seres humanos e do mundo.

\section{O conhecimento: erro e ilusão}

Parafraseando Morin (2011) todo conhecimento tem o risco do erro e da ilusão, pois estes parasitam a mente humana desde os primórdios do Homo Sapiens. E, ainda segundo ele a educação deve apresentar esta questão, dedicando-se à identificação da origem dos erros, ilusões e cegueiras. Segundo a teoria da informação, o erro é o resultado da subjetividade, da visão de mundo e princípios do conhecimento do conhecedor, que ao transmitir a ideia ou a teoria reconstrói através de sua linguagem e pensamento. A projeção dos desejos, dos medos e das emoções multiplicam os riscos do erro.

O desenvolvimento do conhecimento científico pode detectar os erros e a luta contra as ilusões. Os paradigmas que controlam a ciência podem desenvolver a ilusão, visto que nenhuma teoria científica está isenta ao erro e não é capaz de resolver os problemas epistemológicos, filosóficos e éticos. $\mathrm{Na}$ abordagem dos erros mentais, Morin (2011) exalta que cada mente é dotada de um potencial de mentira para si próprio, sendo fonte permanente de erros e ilusões. $\mathrm{O}$ egocentrismo, a necessidade de autojustificativa e a tendência a projetar sobre o outro a causa do mal fazem que cada 
um minta para si próprio, sem detectar esta mentira, da qual, contudo é o autor. Atribui ainda à memória vários erros e ilusões, pois pode na rememoração embelezar ou desfigurar as lembranças, sofrendo influências de projeções ou confusões inconscientes.

Quanto aos erros intelectuais, o autor afirma que as teorias científicas são resistentes aos argumentos contrários e estão imbuídasdo convencimento de sua verdade, refutando qualquer crítica que denuncie seus erros. Morin (2011) apresenta ainda os erros da razão, destacando que a atividade mental ocupa-se de distinguir a vigília do sonho, o imaginário do real, o subjetivo do objetivo, apelando para o controle do ambiente, da prática da cultura, do próximo, ou seja, para a racionalidade corretiva.

$\mathrm{O}$ autor ressalta que a racionalidade construtiva que elabora teorias coerentes está sempre aberta ao que a contesta para evitar que se feche em doutrina, logo a racionalização que se fundamentaria em deduções ou induções que negaria a contestação. A racionalidade critica é a exercida sobre os erros, ilusões das crenças, das doutrinas e teorias. Argumenta que a verdadeira racionalidade dialoga com o real que a resiste, operando sobre a instância lógica e a empírica, sendo argumentativa das ideias e não a propriedade de um sistema de ideias. Esta conhece os limites da lógica, do determinismo e do mecanicismo, reconhecendo que a mente humana não é onisciente e liberta de mistérios.

A verdadeira racionalidade por fim é autocrítica, excedendo a teoria e a crítica ao reconhecer-se suscetível aos erros e ilusões. O princípio da incerteza racional deve permear a educação do futuro. Morin (2011) aborda que os paradigmas são relevantes à educação. Um paradigma pode ser definido por: - Promoção/seleção dos conceitos mestres da inteligibilidade, que seria o nível do princípio de seleção das ideias que são integradas ou rejeitadas no discurso ou na teoria; - Determinação das operações lógicomestres, quando a conceptualização, as operações lógicas são determinadas eas categorias fundamentais da inteligibilidade operam o controle de seu emprego. Os indivíduos conhecem, pensam e agem segundo paradigmas definidos em sua cultura. Um paradigma, ainda instaura relações primordiais, determinando conceitos, comandas, discursos ou teoria. O paradigma cartesiano, por exemplo, separa o sujeito do objeto, levando a dissociações tais como alma/corpo, qualidade/quantidade, sentimento/razão, existência/essência.

O autor supracitado ainda valendo-se do termo Imprinting proposto por Konrad Lorens que o exemplifica utilizando as experiências do animal recém-nascido que ao sair do ovo segue o primeiro ser vivo como se este fosse sua mãe; ressalta que há o 
imprinting cultural que marca os homens desde o nascimento, primeiro com o selo da cultura familiar e a seguir da escolar, prosseguindo na universidade e na vida profissional. Evidencia que o determinismo de paradigmas e modelos explicativos associam-se ao determinismo de convicções e crenças que podem ser tornar forças imperativas do sagrado normalizadora de dogmas e proibitiva do tabu; logo podem transformar-se em doutrinas e ideologias dominantes à sociedade.

O poder imperativo e proibitivo conjunto dos paradigmas, das crenças oficiais, das doutrinas reinantes e das verdades estabelecidas determina os estereótipos cognitivos, as ideias recebidas sem exame, as crenças estúpidas não contestadas, os absurdos triunfantes, a rejeição de evidências em nome da evidência, e faz reinar, em toda parte, os conformismos cognitivos e intelectuais. Todas as determinações propriamente sociais, econômicas e políticas (poder, hierarquia, divisão de classes, especialização e, em nossos tempos modernos, tecnoburocratização do trabalho), e todas as determinações propriamente culturais convergem e sinergizam para encarcerar o conhecimento no multideterminismo de imperativos, normas, proibições, rigidez e bloqueios (MORIN, 2011, p. 27).

Para Morin (2011) é importante estarmos conscientes quanto à noção da noosfera, isto é a esfera das coisas do espírito, tais como deuses, mitos que enriquecem a cultura, produtos de nossa mente e alma que podem interferir em nossas ações e ideias "domesticando-nos", servindo de controle social. O mito e a ideologia podem destruir os fatos. Apresenta um paradoxo quando afirma que devemos lutar contra as ideias, mas só podemos fazê-lo utilizando as ideias, para que possamos identificar o real que reside na ideia, sendo uma tarefa essencial na luta contra a ilusão. Exalta ainda que precisamos estar atentos à manifestação do inesperado, do novo, sendo capaz de rever nossas teorias e ideias.

O conhecer é incerto! Na busca da verdade, as atividades auto-observadoras devem unir-se as atividades observadoras; as autocríticas com as críticas, os processos reflexivos com os de objetivação.

A mente humana deve desconfiar de seus produtos "ideais", que lhe são,ao mesmo tempo vitalmente necessários. Necessitamos estar permanentemente atentos para evitar idealismo e racionalização. Necessitamos de negociação e controlemútuos entre nossa mente e nossas ideias. Necessitamos de intercâmbio e de comunicação entre nossa mente e as diferentes zonas de nossa mente. É preciso tomar consciência do id e do alguém que falam por meio do ego, e é preciso estar sempre alerta para tentar detectar a mentira em si mesmo. 
Necessitamos de que se cristalize e enraíze um paradigma que permita o conhecimento complexo. [...] o problema cognitivo é de importância antropológica, política, social e histórica. Para que haja um progresso de base no século XXI, os homens e mulheres não podem mais ser brinquedos inconscientes não só de suas ideias, mas das próprias mentiras. O deverprincipal da educação é de armar cada um para o combate vital para a lucidez (MORIN, 2011, p. 32 e 33).

Estas ideias convergem com as obras de Nietzsche reescritas por Larrosa (2009) que encontra em seus escritos a visão critica do modelo da formação do homem, da cultura e da sociedade. A realidade estaria interligada a uma construção social de cada sujeito e segundo ele não existem verdades absolutas no mundo, pois a verdade dependeria do contexto histórico de cada pessoa, de cada vida. Nietzsche questionou se os humanos são suficientemente cultos para poder emitir juízo de uma cultura. É apaixonante pensar em ter a habilidade dos jovens pitagóricos que guardavam silêncio durante cinco anos, suspendendo seus juízos sobre as ideias e teorias.

\section{Princípios do conhecimento pertinente}

Morin (2011) evidencia a seguinte questão: como o cidadão do novo milênio poderá ter informações sobre o mundo, sabendo articulá-las e organizá-las? Esta segundo ele é uma questão paradigmática, sendo a questão fundamental da educação, visto que se refereà aptidão de organizar o conhecimento, os saberes divididos, compartimentados e ainda aliados às realidades ou problemas cada vez mais multidisciplinares, transnacionais, globais e planetários. Isto causa um desafio à educação do futuro, quando se deve pensar no contexto, no global, no multidimensional e no complexo. A questão do contexto trata-se de dar sentido aos dados, informações e conhecimento. Bastien (1992) destaca que a contextualização é condição essencial da eficácia do funcionamento cognitivo.

Segundo Morin (2011), o global é mais que o contexto, é o conjunto das diversas partes ligadas a ele de modo inter-retroativo ou organizacional e o todo tem qualidades ou propriedades não encontradas nas partes quando isoladas. O todo deve sempre ser recomposto para que cada parte seja conhecida. Ressalta que o conhecimento pertinente tem que reconhecer o caráter multidimensional enfatizandoque este é uma característica do ser humano (biológico, psíquico, social, afetivo e racional) ou da sociedade (histórica, econômica, sociológica ou religiosa). O complexo é elucidado utilizando o 
termo complexus que significa o que foi tecido junto, pois alguns elementos são inseparáveis e constitutivos de um todo. Entre o objeto do conhecimento e o seu contexto há tecidos interdependente, interativo e inter-retroativo entre as partes e o todo e vice versa, bem como entre as partes entre si. A união entre a unidade e multiplicidade define a complexidade.

A Educação deve promover uma inteligência geral, capaz de lidar com os problemaspelo desenvolvimento de competências particulares ou especializadas e ainda que desenvolva a capacidade de apreender o contexto e o complexo de modo dimensional e dentro da concepção global; sendo assim o conhecimento amplo do mundo é essencial, mobilizando os conhecimentos de conjunto e aprimorando ainda maisessa inteligência.

\begin{abstract}
A educação deve favorecer a aptidão natural da mente em formular e resolver problemas essenciais e, de forma correlata, estimular o uso total da inteligência geral. Este uso total pede o livre exercício da curiosidade, a faculdade mais expandida e a mais viva durante a infância e a adolescência, que com frequência, a instrução extingue e que, ao contrário, se trata de estimular ou, caso esteja adormecida de despertar [...] (MORIN, 2011, p. 39).
\end{abstract}

O autor enfatiza que as mentes formadas pelas disciplinas perdem suas aptidões naturais para contextualizar os saberes e integrá-los em seus conjuntos naturais, provocando o enfraquecimento da percepção do global, da responsabilidade, da solidariedade e dos vínculos com os concidadãos.

A luz de Machado (2000), correlacionando as idéias de Morin (2011) podemos reafirmar a importância da mediação do conhecimento, da relação dialética entre docente e discente e sobre a importância de descrever competênciasdiferenciando-asdas disciplinas; afirmando que as escolas devem almejar não o ensino dos conteúdos disciplinares, mas sim odesenvolvimento das competências pessoais. Ressalta que estudamos matérias, conteúdos disciplinares sem chegar ao conhecimento científico, que asseguraria uma boa formação formal que naturalmente impulsionariaa formação pessoal. Contextualiza ao declarar:

Hoje, parece mais claro que o desenvolvimento científico não pode ser considerado de forma desvinculada do projeto a que serve, que ele se realiza em um cenário de valores socialmente acordados. As ciências precisam servir às pessoas e a organização da escola deve visar primordialmente ao desenvolvimento das competências sociais. [...] (MORIN, 2011, p. 107).

Registra-se a conclusão que se buscará fundamentar: a organização da escola é e continuará a ser marcadamente disciplinar; os professores 
são, e continuarão a ser, professores de disciplinas, não havendo qualquer sentido na caracterização de um professor de "competências" no entanto, urge uma reorganização do trabalho escolar que reconfigure seus espaços e seus tempos, que revitalize os significados dos currículos como mapas do conhecimento que se busca da formação pessoal como a constituição de um amplo espectro de competências e, sobretudo, do papel dos professores em um cenário onde as ideias de conhecimento e de valor encontram-se definitivamente imbricadas (MORIN, 2011, p. 124).

Ademais sugiro tornar o estabelecimento de ensino numa organização aprendiz representando uma prioridade às reformas educacionais necessárias. Fazer com que os professores mobilizem e desenvolvam na "ação" os saberes de ação e inovação indispensáveis aos enfrentamentos dos problemas e desafios que o ambiente complexo lhes impõe.

Segundo Morin (2011) a contextualização é indispensável, pois o recorte das disciplinas não favorece o aprender "o que está tecido junto", como exemplo da economia que é uma ciência social matematicamente avançada, mas humanamente atrasada já que abstraiuas condições sociais, históricas, políticas, ecológicas inseparáveis das atividades econômicas.

O conhecimento especializado é uma forma particular de abstração. A especialização "abs-trai", em outras palavras, extrai um objeto de seu contexto e de seu conjunto; rejeita os laços e as intercomunicações com seu meio; introduz o objeto no setor conceptual abstrato, que é o da disciplina compartimentada, cujas fronteiras fragmentam arbitrariamente a sistemicidade (relação da parte com o todo) e a multimensionalidade dos fenômenos; conduz à abstração matemática que opera de si própria uma cisão com o concreto, privilegiando tudo que é calculável e passível de ser formalizado [...] (MORIN, 2011, p. 42).

Destarte o produto da educação que recebemos compartimentada e que não une os conhecimentos nos leva a dificuldades de organizar o saber e à "atrofia da disposição mental natural de contextualizar e globalizar. Outra variável que interfere no conhecimento é a que é chamada de "falsa racionalidade", ou seja, racionalização abstrata e unidimensional, a dominação da inteligência pelo pensamento tecnocrático, que é pertinente às máquinas artificiais, mas incapaz de compreender o ser humano já quea concebemos o ser humanocomo único ser racional. Como decorrência a dificuldade de compreensão e visão em longo prazo dos problemas graves que a humanidade possui e que carece de cidadãos preparados para lidar com estes. 
É fato que houve grandes avanços em todas as áreas do conhecimento científico no século XX, todavia gerou a "cegueira", erros e ilusões dos cientistas, técnicos e especialistas frente aos problemas globais, fundamentais e complexos.

\title{
Ensinar a condição humana
}

Morin (2011) assinala que a educação do futuro deverá ter o ensino centrado na condição humana e ainda reconhecer sua diversidade cultural inerente, pois todo conhecimento; deverá situar o humano no universo; contextualizar seu objeto e responder as questões: Quem somos? Onde estamos? De onde viemos? Para onde vamos?

\begin{abstract}
Para a educação do futuro, é necessário promover grande remembramento dos conhecimentos oriundos das ciências naturais, a fim de situar a condição humana no mundo; dos conhecimentos derivados das ciências humanas, para colocar em evidência a multidimensionalidade e a complexidade humanas, bem como para integrar (na educação do futuro) a contribuição, inestimável das humanidades, não somente a filosofia e a história, mas também a literatura, a poesia, as artes (MORIN, 2011, p.48).
\end{abstract}

Para Morin (2011) o ser humano traz consigo o enraizamento e o desenraizamento das condições cósmicas, físicas, terrestres e a condição humana, quando nesta última o papel da hominização é destacado como primordial à condição humana. A hominização leva a um novo início e o conceito de homem reúne os princípios biofísico e psicossociocultural, um remetendo ao outro. Segundo o autor o ser humano é constituído de unidualidade (é um ser, a um só tempo, plenamente biológico e cultural, trazendo a unidualidade originária, todavia a cultura acumula em si o que é conservado, transmitido, aprendido e comporta normas e princípios de aquisição). Ademais o homem só se realiza plenamente como ser humano pela cultura e na cultura. A relação cérebro-mente-cultura se faz; a mente humana é uma criação que emerge e se afirma na relação cérebro-cultura. A mente é o surgimento do cérebro que suscita a cultura, que não existiria sem o cérebro.

Outra tríade importante é a bioantropológica que decorre da concepção do cérebro triúnico de MacLean (1970) que contém paleocéfalo (fonte de agressividade, do cio e das pulsões primárias); mesocéfalo (ligado ao desenvolvimento da afetividade e da memória em longo prazo); o córtex (sede das aptidões analíticas, lógicas e 
estratégicasque a cultura atualiza frequentemente). A relação entre estas são complementares e antagônicas, chamada de pulsão, coração e razão. Esta relação triúnica não obedece à hierarquia razão-afetividade-pulsão; há uma relação instável entre estas três instâncias.

O indivíduo ainda está associado à sociedade e espécie, quando destaco a nível antropológico que a sociedade vive para o indivíduo e vice-versa, porém é a cultura e a sociedade que garantem a realização dos indivíduos e as relações entre estes asseguram a perpetuação da cultura e a auto-organização da sociedade.

A complexidade humana não poderia ser compreendida dissociada dos elementos que a constituem: todo desenvolvimento verdadeiramente humano significa o desenvolvimento conjunto das autonomias individuais, das participações comunitárias e do sentimento de pertencer à espécie humana (MORIN, 2011, p. 55).

Na obra que agora reescrevo há ao destaque da importância da educação cuidar da unidade da espécie humana sem negligenciar a diversidade. A concepção da unidade do múltiplo e da multiplicidade do uno é indispensável, pois cada ser carrega a esfera individual (singularidade anatômica e fisiológica. Existe a unidade/diversidade cerebral, mental, psicológica, afetiva, intelectual e subjetiva com suas singularidades) A outra esfera, a social compreende as organizações sociais e as culturas. A cultura é o conjunto dos saberes, dos afazeres, das regras, das normas, das proibições, das estratégias, das crenças, dos valores, dos mitos que são transmitidos ao longo das gerações e reproduzidos pelos indivíduos, controlando a existência da sociedade e mantendo a complexidade psicológica e social.

Morin (2011, p. 57) ao mencionar o duplo fenômeno da unidade e da diversidade das culturas, ainda assinala "A cultura mantém a identidade humana naquilo que tem de específico; as culturas mantêm as sociedades sociais naquilo que tem de específico". Afirma que a desintegração de uma cultura, sob o efeito da dominação técnicocivilizacional, é uma perda para toda humanidade. Complementa que o ser humano é singular e múltiplo que:

Traz em si multiplicidades interiores, personalidades, uma infinidade de personagens quiméricos, uma poliexistência no real e no imaginário do sonho e na vigília, na obediência e na transgressão, no ostensivo e no secreto, balbucios embrionários em suas cavidades e profundezas insondáveis. Cada qual contém em si galáxias de sonhos e de fantasmas, impulsos de desejos e amores insatisfeitos, abismos de 
desgraças, imensidões de indiferença gélida, queimações de astro em fogo, acessos de ódio, desregramentos e lampejos de lucidez, tormentas dementes (MORIN, 2011, p. 57 e 58).

A complexidade do ser humano o faz possuidor de caracteres antagonistas: sábio e louco, trabalhador e lúdico, empírico e imaginário, econômico e consumista, prosaico e poético, não vivendo somente de racionalidade e de técnica. Uma atividade técnica, prática, intelectual se depara com a inteligência empírico-racional, tais como atividades de jogos, de festas, de ritos que funcionam por vezes como pausas antesdo retorno à vida prática ou para o trabalho. Estão presentes ainda as manifestações entre o psiquismo, a afetividade, a magia, o mito e a religião; no ser humano o desenvolvimento do conhecimento racional-empírico-técnico jamais anulou o conhecimento simbólico, mítico, mágico ou poético.

É certo que o ser humano é complexo, oscilando do racional e irracional, sujeito aintensa e instávelafetividade; logo cabe a educação precisa de vocações que examinem e estudem esta complexidade, apresentando o destino multifacetado do serhumano: enquanto espécie humana, individualidade, sociabilidade, historicidade e suas interrelações.

\section{Ensinar as incertezas}

Morin (2011, p. 79) afirma que "Grande conquista da inteligência seria poder, enfim, libertar-se da ilusão de prever o destino humano." A despeito de existir determinantes econômicas, sociológicas, históricas e outras, precisamos ter consciência de que a história humana é contínua e desconhecida. Reafirmando tal citação elenca vários acontecimentos, tratados e guerras citando suas intenções e consequências inesperadas. Não linearidade na história, pois ela é um complexo de ordem,desordem e organização. Menciona que o surgimento do novo não é previsível, pois não seria novo. A criação não pode ser antecipada, senão não haveria criação.

Toda evolução é fruto do desvio bem-sucedido cujo desenvolvimento transforma o sistema onde nasceu: desorganiza o sistema, reorganizando-o. As grandes transformações são morfogêneses, criadoras de formas novas que podem constituir verdadeiras metamorfoses. De qualquer maneira, não há evolução que não seja desorganizadora/reorganizadora em seu processo de transformação ou metamorfose (MORIN, 2011, p. 82). 
A humanidade se aventura em sua esfera e continua no dever de criações e destruições. Enfrentar as incertezas numa época repleta de mudanças, valores ambivalentes é um desafio que a educação do futuro deve considerar, pois o conhecimento é incerto, sendo um emaranhado de princípios: - da incerteza cérebromental (decorrente da tradução/reconstrução próprio a todo conhecimento); - da incerteza lógica (a verdade ou falsidade presente na contradição); - da incerteza racional (a falta da autocrítica na racionalidade leva a racionalização); - da incerteza psicológica (presente nos limites do autoconhecimento e na dificuldade do autoexame crítico).

Segundo Morin (2011, p. 85) surge uma nova consciência: "a humanidade é conduzida para uma aventura desconhecida" A solidariedade humana não é suficiente para dissipar o ódio de raça, da inimizade um dos outros, da diferença de ideologias que levam às guerras, massacres. “[...]. Os processos são destruidores de um mundo antigo, aqui, multimilenar, ali, multissecular. A humanidade não consegue gerar a Humanidade $[\ldots]$.

A humanidade carrega consigo as incertezas: incerteza do real (necessidade de saber interpretar a realidade antes de reconhecer onde está o realismo); do conhecimento (o conhecimento carrega o risco de ilusão e erro); as incertezas e ecologia da ação (a ação é decisão, escolha, mas é também uma aposta. E, na noção de aposta, há a consciência do risco e da incerteza. Na ecologia da ação, as intenções escapam, as interações são apossadas pelo meio ambiente, a complexidade, o acaso, a iniciativa, a decisão fica a derivas e transformações).

Ademais a humanidade convive com circuitos: - risco-precaução (a ação empreendidasofre o risco da contradição entre os princípios do risco e precaução, sendo um necessário ao outro); - fins-meios (reside na incerteza de que nem sempre a pureza dos meios conduz aos fins desejados, nem a impureza a nefasta); ação-contexto (há a possibilidade do desvio ou de perversão do sentido inicial da ação pelas intervenções e variáveis do meio).

Outrossim, é a imprevisibilidade em longo prazo, pois uma ação pode ser modificada, anulada ou empreendida, nunca estando segura de ocorrer no sentido de sua intenção inicial. O enfrentamento da incerteza da ação perpassa pelo consciente da aposta contida na decisão e na estratégia.A estratégia sobrepõe-se ao programa,pois este pode estabelecer uma sequência de ações a serem executadas, mas pode ser bloqueado, todavia a estratégia carrega um cenário de ação que examina as certezas e incertezas, a probabilidade e improbabilidade da situação. Morin (2011, p. 91) assinala: “'[...] É na 
estratégia que se apresenta sempre de maneira singular, em função do contexto e em virtude do próprio desenvolvimento, o problema da dialógica entre fins e meios[...]".

$\mathrm{Na}$ história as incertezas é o único marco, as possibilidades humanas permanecem impossíveis de se realizar, porém o inesperado, o improvável torna-se possível e se realiza, a humanidade espera o inesperado e trabalha pelo improvável.

\section{Ensinar a compreensão}

Parafraseando Morin (2011) os sistemas educacionais avançaram por redes, telefonia, modems, internet, mas não levou ao alcance da compreensão humana, que deveria ser uma das finalidades da educação, contemplando ainda a missão espiritual e de garantia da solidariedade intelectual emoral da humanidade. Ressalta ainda que o problema da compreensão que incidiu no polo planetário (encontros e relações entre pessoas, culturas e povos de diferentes origens culturais) e polo individual (envolve as relações particulares entre os próximos, visto que a proximidade pode levar ao ciúme, agressividade, mal-entendidos).

O autor discorrendo acerca da compreensão humana destaca que a comunicação nem sempre garante a mesma. Assinala que existem dois tipos de compreensão; a intelectual ou objetiva e a humana intersubjetiva. Para compreensão intelectual ou objetiva, a explicação pode ser suficiente para descrever as coisas anônimas ou materiais, mas a compreensão humana vai além da explicação. Em relação à compreensão humana intersubjetiva menciona que compreender inclui um processo de identificação, de empatia e de projeção e exige que o tanto nós como o outro estejamos abertos, com simpatiae generosidade

Morin (2011) elenca vários obstáculos à compreensão, tais como: -ruído (que cria mal-entendidos ou não entendido); - polissemia de uma noção que enunciada em um sentido é entendida de outro; - ignorância de ritos e costumes do outro (como exemplo os ritos de cortesia que pode ate ofender inconscientemente); - incompreensão dos valores imperativos propagados pela cultura (tradições, preceitos, obediência incondicional); - incompreensão dos imperativos éticos próprios a uma cultura (o imperativo de vingança numa sociedade tribal pode ser um exemplo); - a visão de mundo impossibilitando a compreensão de ideias ou argumentos de outra visão diferenciada; e ainda impossibilidade da compreensão de uma estruturamensal em 
relação à outra. Acrescenta ainda a possibilidade de sobrepor-se, de considerar-se o centro do mundo, sendo estranho e hostil tudo que for distante, como o egocentrismo, o etnocentrismo, o sociocentrismo e o espírito redutor que pose der representada pela possessão de uma ideia, uma fé, uma convicção absoluta de algo como verdade.

Destarte aborda a importância da ética da compreensão, quando não há expectativa de reciprocidade do outro, há o ímpeto de compreender de modo desinteressado, é a abertura a argumentação, é refutar a condenação precipitada de algo, é o bem pensar que permite apreender em conjunto o texto e o contexto, o ser e seu meio ambiente, o local e o global, o multidimensional, o complexo que são as condições desencadeadoras do comportamento humano. É essencial ainda a ética, a introspecção para que possamos praticar mentalmente o auto-exame crítico e a necessidade de descentrarmos de nós mesmos para perceber o outro e que somo também passíveis, por exemplo, de falhas, quando será necessária a mútua compreensão.

O ser humano é muito complexo e compreendê-lo exige muita reflexão, apreensão de lições de vida, compreensão dos sofrimentos, acreditar na possibilidade de cada um autorreformar-se. Estar aberta ao outro, interiorizar a verdadeira tolerância, exercitar a aceitação de ideias e convicções e respeito às escolhas e posições divergentes da nossa.

Morin (2011) evidencia quatro graus de tolerância, a primeira atribuída a Voltaire que se refere a respeitar o direito de proferir um propósito que parece desprezível; o segundo é inseparável da opção democrática que pode ser vista como nutrir-se de opiniões diversas e antagônicas a sua; o terceiro grau atribuído a Niels Bohr é concebido pela percepção de que uma ideia profunda é outra ideia profunda dita de outra forma e há uma verdade antagônica que é preciso respeitar. O quarto grau vem das possessões humanas, mitos, ideologias. A tolerância vale, com certeza, para as ideias, não para os insultos, as agressões ou atos homicidas.

As culturas devem aprender umas com as outras e se tornar uma cultura aprendiz. A compreensão integra aprender e reaprender. Outra questão essencial envolve a ética relacionada à compreensão entre as pessoas e a era planetária, que pede a mundialização da compreensão que estaria a serviço do gênero humano, da solidariedade intelectual e moral da humanidade.

\section{Considerações finais}


Edgar Morin (2011) discursa suas ideias propondo a reflexão de questões planetárias, alegando que sua obra: Os sete saberes necessários à educação do futuro não comporta bibliografia, justificando que a bibliografia considerável, difícil de selecionar, atribui ao leitor formar a própria opinião, a realização de leituras e destacando que cada país dispõe de obras provenientes da própria cultura. Desta forma me faz recordar Nietzsche:

Nietzsche sabe que a possibilidade da leitura não só depende do difícil domínio da arte da filologia e do raro luxo das condições que requer,mas, também, e sobretudo, do tipo de pessoa que é o leitor. A experiência da leitura não consiste somente em entender o significado do texto mas, em vivê-lo. E a partir deste ponto de vista que ler, coloca em jogo o leitor em sua totalidade. Ler exige certa afinidade vital e tipológica entre o leitor e o livro. Mas o "eu" do leitor não é outra coisa senão o resultado superficial de certa organização hierarquizada de forças que, em grande medida, permanece inconsciente. O que somos capazes de ler em um livro é o resultado de nossas disposições anímicas mais profundas: a finura e o caráter de nossos sentidos, nossas disposições corporais, nossas vivencias passadas, nossos instintos, nosso temperamento essencial, a qualidade de nossas entranhas.[...] (LARROSSA, 2009, p. 45).

E ainda, Nietzsche (apud Larrosa, 2009) quando aspira um leitor que leia com todo o corpo:

\begin{abstract}
Ler bem é saber ver tudo aquilo que o texto mostra, e também adivinhar o que a literalidade do texto não mostra, isto é, a força que expressa[...] saber distinguir óticas textuais [...] as perspectivas dogmáticas $[\ldots\}$ as visões "desinteressadas" que nos dão uma realidade sem paixão, sem paixão, sem orientação. Ler bem é olhar ativamente, olhar com os olhosmúltiplos e interessados, saber utilizar "a diversidade das perspectivas e das interpretações nascidas dos afetos". Porque "quanto maior for o número de afetos aos quais permitamos dizer sua palavra sobre uma coisa, quanto maior for o número de olhos, de olhos diferentes que saibamos empregar para ver uma coisa, tanto mais completo será nosso "conceito"delatanto mais completa será nossa objetividade[...].
\end{abstract}

E por que recordar Nietzsche? Edgar Morin tem concepções abrangentes e por vezes de caráter filosófico, permeiam por valores, saberes, competências, ideologias individuais que precisam ser disseminadas na coletividade. Estas questões elencadas como necessárias à educação do futuro são significativas, reflexivas e pertinentes, mas carecem de ser operacionalizadas, devem constituir-se em um projeto educativo paradigmático e que carece de contar com atores educacionais preparados, críticos e que tenham uma formação sólida, pois é "a chave" para sua implementação, para sua 
viabilização. Requer competência! Sendo assim recorro a recente reescrita das ideias de Perrenoud (1999) que competência pode ser considerada segundo três características: tomada de decisão, mobilização de recursos e saber agir, enquanto construção, coordenação e articulação de esquemas de ação ou de pensamento. Igualmente elejo Macedo (2001) que complementa esta ideia:

Ser competente é ousar julgar em momentos de incerteza, dificuldade, ambivalência, contradição, dúvida e, por isso, ser competente é ser tolerante, generoso. Tolerante no sentido de aperfeiçoamento, correção, retomada e, com modéstia, ver os diferentes aspectos que devem ser considerados em função de um contexto, de uma história e configuração atual [...] (MACEDO, 2001, p. 65).

Morin (2011) em sua obra de caráter íntimo e de grande personalismo reflete variáveis atuais de grande importância mundial, expostas convergentemente por outros escritores e pensadores educacionais, elencou algumas contracorrentes, descritas anteriormente, que a meu ver é a esperança prevista para o terceiro milênio, mas penso que suas proposições são emblemáticas e requer realmente uma reforma total do pensamento da espécie humana. Depositar somente na Educação do Futuro a concretização de seu ideal é utópico, considerando que precisamos de um exército para concretizá-la, quando os governantes, os cidadãos precisarão movimentar-se e dialogar exaustivamente construindo um projeto de vida que culmine numa consciência planetária. Todavia façamos a nossa parte, sejamos os primeiros a propor pequenas revoluções, vários riachos desembocam num grande rio. Vamos rever concepções e preparar uma consciência de pensamento que levará a sinergia e ações.

Que a ideologia de Morin (2011) nos assole... nos leve a ensinar...e aprender a aprender, construindo um projeto maior...um projeto educacional...um projeto com dimensões planetárias. A educação assim é apontada como essencial à compreensão humana em todos os níveis e segmentos educacionais. Como educadores façamos uma mudança em nós... vamos disseminar estes saberes, façamos uma ressignificação do nosso ser e fazer pedagógico, implementemos mudanças que a humanidade precisa, reflitamos as ideias de Edgar Morin e comecemos a fazer "algo novo"... possível... ético, pois "o conhecimento compromete-nos" no mínimo a tomar uma atitude... buscar um caminho para nossa "cidadania terrena".

\section{Referências}


BASTIEN, C. Le décalage entre logique et connaissance. Courrier Du CNRS: Siences Cognitives, n.79, out. 1992.

LARROSA, J. Nietzsche \& a Educação. traduzido por Seríramis Gorini da Veiga. 3 ed. Belo Horizonte: Autêntica, 2009.

MACEDO, L. Prefácio. In: PERRENOUD, P. Ensinar: Agir na urgência e decidir na Incerteza. Porto Alegre: Artmed, 2001.

MACHADO, N. J. Educação, projetos e valores. São Paulo. Escrituras Editora, 2000.

MACLEAN, P. D. The triune brain. In: SMITH, F. Q. (Ed.). The Neurosciences, Second Study Program. New York: Rockefeller Press. 1970.

MORIN, E. Os sete saberes necessários à educação do futuro. Tradução de Catarian Eleonora F. da Silva e Jeanne Sawaya. São Paulo: Cortez; Brasília, DF: UNESCO, 2011.

PERRENOUD, P. Pedagogia Diferenciada: das intenções à ação. Porto Alegre: Artmed, 1999.

\section{Como referenciar este artigo}

CARVALHO, Igor Leandro Alves de. Os sete saberes necessários à educação do futuro: reflexões e um novo olhar sobre o tema. Revista Ibero-Americana de Estudos em Educação, Araraquara/SP, v. 11, n. esp. 2, p.861-880, 2017. Disponível em: <http://dx.doi.org/10.21723/riaee.v12.n1.6993>. E-ISSN: 1982-5587.

Data de submissão: maio/2014

Aprovação final: nov/2016 